\title{
Robustness of Risk Maps and Survey Networks to Knowledge Gaps About a New Invasive Pest
}

\author{
Denys Yemshanov, ${ }^{1, *}$ Frank H. Koch, ${ }^{2}$ Yakov Ben-Haim, ${ }^{3}$ and William D. Smith ${ }^{4}$
}

\begin{abstract}
In pest risk assessment it is frequently necessary to make management decisions regarding emerging threats under severe uncertainty. Although risk maps provide useful decision support for invasive alien species, they rarely address knowledge gaps associated with the underlying risk model or how they may change the risk estimates. Failure to recognize uncertainty leads to risk-ignorant decisions and miscalculation of expected impacts as well as the costs required to minimize these impacts. Here we use the information gap concept to evaluate the robustness of risk maps to uncertainties in key assumptions about an invading organism. We generate risk maps with a spatial model of invasion that simulates potential entries of an invasive pest via international marine shipments, their spread through a landscape, and establishment on a susceptible host. In particular, we focus on the question of how much uncertainty in risk model assumptions can be tolerated before the risk map loses its value. We outline this approach with an example of a forest pest recently detected in North America, Sirex noctilio Fabricius. The results provide a spatial representation of the robustness of predictions of $S$. noctilio invasion risk to uncertainty and show major geographic hotspots where the consideration of uncertainty in model parameters may change management decisions about a new invasive pest. We then illustrate how the dependency between the extent of uncertainties and the degree of robustness of a risk map can be used to select a surveillance network design that is most robust to knowledge gaps about the pest.
\end{abstract}

KEY WORDS: Decision theory; info-gap; robustness to uncertainty; Sirex noctilio; survey network

${ }^{1}$ Natural Resources Canada, Canadian Forest Service, Great Lakes Forestry Centre, 1219 Queen Street East, Sault Ste. Marie, ON P6A 2E5, Canada.

${ }^{2}$ Department of Forestry and Environmental Resources, North Carolina State University, USDA Forest Service, Forest Health Monitoring Program, 3041 Cornwallis Road, Research Triangle Park, NC 27709, USA.

${ }^{3}$ Technion, Israel Institute of Technology, Faculty of Mechanical Engineering, Haifa 32000, Israel.

${ }^{4}$ USDA Forest Service, Southern Research Station, 3041 Cornwallis Road, Research Triangle Park, NC 27709, USA.

* Address correspondence to Denys Yemshanov, Natural Resources Canada, Canadian Forest Service, Great Lakes Forestry Centre, 1219 Queen Street East, Sault Ste. Marie, ON P6A 2E5, Canada; tel: 705-541-5602; fax: 705-541-5700; dyemshan@nrcan.gc.ca.

\section{INTRODUCTION}

Invasive alien species cannot be managed at meaningful spatial or temporal scales without prediction of the risks and impacts associated with invasion. Assessing invasion risk typically involves ranking the level of threat posed by an invading organism to various geographic locations, which is accomplished by identifying the pathways and processes of its introduction and movement, its susceptible hosts or habitats, and its potential ecological and economic impacts. ${ }^{(1-3)}$ Risk maps, as the spatially explicit realizations of these assessments, are one of the elements that may guide policymakers in their decision process regarding where to target management actions for a pest. ${ }^{(2,4)}$ These maps are usually based on underlying conceptual or quantitative models that 
depict important ecological and environmental aspects of invasions, such as climatic suitability, ${ }^{(5,6)}$ entry, ${ }^{(7)}$ spread and establishment. ${ }^{(8-11)}$ These models are commonly formulated from established analytical concepts of invasion spread, ${ }^{(12-16)}$ but require certain parameters to be derived from prior knowledge about the invading organism; current or historical observations are usually applied to make informed estimates of the true parameter values. Finding the true values would require extensive observational data, which can in some cases be obtained through long-term monitoring programs, ${ }^{(17-19)}$ but are rarely available for new invaders. Information regarding new invaders may be available from other geographic regions where the species is known to occur, but even if well specified, does not address the additional issue that an invader may behave differently in a new environment. ${ }^{(20-22)}$ Thus, risk maps may be built upon imprecise data or ill-defined model assumptions, leading to undetected errors about a new pest ${ }^{(23,24)}$ and misconceptions about the risks of invasion. ${ }^{(25,26)}$

Several techniques have been proposed to quantify uncertainties, with sensitivity analysis among the most widely used. ${ }^{(24)}$ Sensitivity analysis involves systematic alterations of model parameter (or input) values in order to observe their relative contribution to variation and uncertainty in the target output variable. ${ }^{(27-29)}$ Sensitivity analysis in its traditional form may be inefficient in cases where large possible variations of the model parameters that lead to a worst-case outcome are unknown. A number of other methods use probability distributions to represent uncertainty; however, with respect to estimating risks for emerging invasive pest threats, probability models may be inadequately formulated because of the very high importance of rare events (i.e., events associated with the extreme tails of the distribution), which most probability models do not describe well. ${ }^{(30)}$

Ensemble prediction systems ${ }^{(31,32)}$ that combine the forecasts made with different models represent another alternative, in this case addressing, at least in part, uncertainty due to model structure or formulation. ${ }^{(33,34)}$ Several other studies have attempted to solve the issue of severe lack of knowledge through multi-criteria decision analysis and valuation. ${ }^{(35-37)}$ The general idea of these efforts is to translate vague objectives into more precise performance indicators. These techniques, nevertheless, still require knowledge of the structure of uncertainty, which for new invasive pests is typically lacking.

\subsection{Information Gap Analysis}

Alternatively, the information gap concept (infogap hereafter) formulates the problem of uncertainty in terms of a gap between what is known and what has to be known in order to make reliable assessments. ${ }^{(30)}$ Briefly, it evaluates the choices for a particular decision and focuses on the following question: How wrong can the data and underlying models be, while the outcome of the decision in question remains acceptable? Info-gap requires very limited prior knowledge about the structure of uncertainty in the system being modeled; it assumes an unknown and unbounded horizon of uncertainty. ${ }^{(30,38)}$ The approach introduces the concept of robustness of a given decision alternative to uncertainty. Compared to other decision methods that maximize the potential utility of the outcome by exhaustively exploiting the best-estimated data and models, the info-gap approach focuses on the robustness of an acceptable outcome to errors in those data and models.

Typically, the info-gap framework includes three components: a "process" model, a performance requirement, and a model for uncertainty. The process model is a formalized representation of the system of interest that incorporates the elements considered most important and truthfully rendered. ${ }^{(30,38)}$ It is used to evaluate the potential decision alternatives (which could mean different actions or policy objectives). The evaluation of each decision choice, $\psi$ (a "scenario" hereafter), is usually associated with a vector of $i$ process model assumptions, $x_{1}, x_{2}, \ldots, x_{i}$. The values of $x_{i}$ can be, for example, model parameter values or functional relations that portray key assumptions about the system; in the case of species invasions, parameters such as host susceptibility or rate of spread are likely to be relevant. Under one info-gap approach, the $x_{i}$ values are used to calculate corresponding utility functions, $v_{i}$, which are aggregated via relative scaling factors (or probabilities that may be uncertain), $\beta_{i}$, to an expected utility metric, $V_{\psi}(x)$. The $V_{\psi}(x)$ can be calculated in a variety of ways, ranging from a simple additive sum of $\beta_{i} \cdot v_{i}$ to more complex computations (see BenHaim $^{(30)}$ for further discussion). The expected utility metric value for each decision scenario $\psi$ is evaluated in terms of the performance requirement. The performance criteria usually assess the utility metric value computed with the process model against a certain threshold:

$$
V_{\psi}(x) \geq V_{\min },
$$


hence requiring the expected utility to be equal to or above the critical value, $V_{\min }$. The uncertainty model describes what is unknown about the parameters or functions $x_{i}$ in the process model. It is often possible to assume some prior information exists regarding the parameters or functional relations, which may be represented by their nominal values, $\bar{x}_{i}$. However, it is impossible to exactly specify how much the actual values deviate from these nominal values. The uncertainty model typically assumes that, for each scenario, any $x_{i}$ deviates by an unknown fraction from its nominal value, $\bar{x}_{i}$ and an uncertainty parameter, $a$, also referred to as the horizon of uncertainty, denotes this unknown degree of deviation. For each parameter $x_{i}$, the horizon of uncertainty can also be rescaled by factor $w_{i}$ based on prior information about the relative variability of $x_{i}$ (alternatively, $w_{i}=1$ if no prior information is available).

There are many types of info-gap models of uncertainty. The simplest is the uniform-bound model, $H(a)$, which contains an unbounded family of nested intervals for each $a \geq 0$ :

$$
\begin{gathered}
H(a)=\left\{x: \max \left[0,\left(1-w_{i} a\right) \bar{x}_{i}\right] \leq x_{i} \leq\left(1+w_{i} a\right) \bar{x}_{i},\right. \\
i=1, \ldots, k\}, a \geq 0,
\end{gathered}
$$

where each parameter $x_{i}$ deviates from its nominal value by a proportion $w_{i} a$ or less, satisfying the condition $x_{i} \geq 0$. The info-gap uncertainty model is used in part to estimate the robustness of a given scenario as the greatest value of the uncertainty horizon, $a$, that guarantees an expected utility, $V_{\psi}(x)$, to be no less than the critical threshold $V_{\min }$, that is, $V_{\psi}(x) \geq$ $V_{\min }$. This can be formulated by defining a set of finite acceptable uncertainty horizons, $a$, at which a given scenario still generates a valid outcome.

\section{METHODS}

\subsection{Risk Mapping Application}

In this article, we explore a methodology for estimating how wrong key assumptions about an invading organism can be without compromising estimates of invasion risk and their mapped representations, and without compromising survey decisions. We consider large possible variations in model parameters and do not assume knowledge of the conditions comprising the worst-case outcome. We begin by using a spatial simulation model to generate a map of infestation risks and then use the info-gap concept to assess how the properties of the risk map may affect decisions about monitoring of a new pest. Our first objective is to explore the robustness of the risk map to uncertainty. We identify geographical hotspots within the study area where the uncertainties are likely to affect the invasion risk estimates and their variation. This is an important consideration because risk maps may serve as a starting point in planning monitoring or quarantine efforts for invasive organisms. ${ }^{(4,39-41)}$ Subsequently, we apply the results to compare and choose the best (i.e., the most robust) of several alternative pest surveillance networks designed to facilitate long-term monitoring efforts.

\subsection{Species of Interest}

Our study focuses on Sirex noctilio Fabricius, a woodwasp recently detected in the northeastern United States ${ }^{(42)}$ and eastern Canada. ${ }^{(43)}$ During the past few years, $S$. noctilio has expanded beyond the initial detections, and since most subboreal areas in eastern North America are believed to be climatically suitable for the species, ${ }^{(44)}$ it is considered a serious threat to pine (Pinus spp.) forests throughout the region. ${ }^{(45-47)}$ The few available field data indicate that $S$. noctilio preferentially attacks nonnative pine species in the eastern United States and Canada, but native pines are also susceptible. ${ }^{(43,48)}$ There is little certainty regarding the woodwasp's behavior in North America, as the bulk of quantitative knowledge about its ecology is based on studies in the Southern Hemisphere ${ }^{(44,47-49)}$ where S. noctilio is a pest attacking plantations of introduced pines.

\subsection{Risk Mapping Model}

For this study, we created maps of $S$. noctilio invasion risk using a dynamic simulation model described in Yemshanov et al. ${ }^{(10,11)}$ Our approach differs from traditional, static risk assessments performed with bioclimatic niche or similar models $^{(5,6,39,44)}$ in that we depict the progress of invasion over a given forecast horizon (i.e., we do not assume the invasion has already reached equilibrium). Briefly, we used the Canadian Forest Service Forest Bioeconomic Model, CFS-FBM, ${ }^{(10,11)}$ to generate spatial predictions of $S$. noctilio spread and impact on pine host resources across eastern North America. At each time step, $S$. noctilio disperses from currently infested locations (i.e., map cells) or from potential new entries at U.S. and Canadian marine port locations as a result of international trade. The 
probability that $S$. noctilio will successfully establish in a new location depends on the geographical distribution, composition, and age of the host resource (i.e., pine stands). If successfully established, the new $S$. noctilio population is expected to cause mortality of hosts over time and also serve as a nucleus for further expansion of the invasion. Here, we concisely summarize the model characteristics germane to this study; please see Yemshanov et al. ${ }^{(10,11)}$ and Koch et al. ${ }^{(50)}$ for more details regarding the CFSFBM model and the risk mapping approach.

The simulations started from a 2006 map of known $S$. noctilio infestations, ${ }^{(43,51)}$ followed by anticipated new introductions in subsequent years at marine ports in the United States and Canada. The pest's potential for future entry into eastern North America was modeled as a function of the value of imported commodities ${ }^{(52,53)}$ and also incorporated the impact of new international phytosanitary standards for all wood packaging and raw wood materials, ${ }^{(54)}$ which were implemented by the United States and Canada in 2006. The entry potential was assumed to drop by $50 \%$ in 2007 following the adoption of the new standards and then grow at a $7 \%$ annual rate (see the "high-risk" scenario in Yemshanov et al..$^{(11)}$ ). For each port, a local probability of entry, $W_{\mathrm{x}(t)}$, was calculated from the volumes of received shipments of commodities capable of harboring S. noctilio ${ }^{(55)}$ and ranged between 0.0008 and 0.094 per year. ${ }^{(11)}$

The successful entries and existing infestations were then used to simulate spread of the pest in eastern North America utilizing a coalescing colony model. ${ }^{(10,11,56)}$ The population spread was estimated as dependent on the probability of colonization in the nearest adjacent map location, $p_{0}$, and the distance, $d$, from the nearest known infested location, constrained by the maximum distance, $d_{\max }$, at which new locations may be successfully invaded. In successfully invaded locations, the maximum annual $S$. noctilio population size and the total damage to host was constrained by a carrying capacity, $k .^{(10,50)}$

The establishment of $S$. noctilio populations depended on availability and susceptibility of hosts (pines). The susceptibility, $s_{\mathrm{v}}$, sets the establishment probability for new colonies and was modeled in this case as a species-specific function of pine stand age constrained by the maximum value, $s_{\max }$. Higher $s_{\mathrm{v}}$ and $s_{\max }$ values generally translate to a higher chance of pest survival and more severe host damage. Based on USDA Forest Service susceptibility ratings ${ }^{(57)}$ we divided pine species into two groups, with $s_{\max }=$ 0.95 for species in "very high" and "high" suscep- tibility groups and $s_{\max }=0.5$ for species in "low" and "medium" groups. Insufficient host resource may hold the S. noctilio population size below the carrying capacity and limit the overall infestation potential at a given time step. Therefore, the model also required tracking the geographical distribution of pine forests and their growth over time. Maps of pine composition and age were derived from the National Forest Inventory for Canada ${ }^{(58)}$ and the USDA Forest Service Forest Inventory and Analysis database. ${ }^{(59,60)}$ The growth of the pine resource and the amount of host surviving after $S$. noctilio infestation were modeled via growth rate curves, $g_{j(t)}$, defined separately for the United States ${ }^{(61)}$ and Canada ${ }^{(10)}$ (see prior studies $^{(11,50)}$ for details).

We used the simulation model to generate risk estimates conforming to a definition of risk as the probability of an undesired event along with some representation of the consequences of the event. ${ }^{(62)}$ Based on multiple model replications, we calculate risk for each geographical location $j$ in eastern North America as the probability of $S$. noctilio invasion, $P_{j}$, within a given time horizon (30 years in this study):

$$
P_{j}=\frac{\sum_{d=1}^{D_{\text {reps }}} \tau_{j, d}}{D_{\text {reps }}} \forall \tau_{j, d}=[0 \mid 1],
$$

where $\tau_{j, d}$ is the presence-absence of an infestation in map cell $j$ at the end of the forecast horizon for a single model replication $d$, and $D_{\text {reps }}$ is the total number of model replications. Essentially, $P_{j}$ describes the risk of finding relatively large, established $S$. noctilio infestations within an area at least equal to the map spatial resolution. We also characterized the variation of $P_{j}$ values with their standard deviations, $\sigma_{j}$, as a measure of output uncertainty.

\subsection{Analysis Overview}

We adopted an info-gap approach to explore how uncertainties in key risk model parameters affect the utility of the output risk maps and pest surveillance networks. Our concept of using robustness in a spatial setting is somewhat similar to the studies of Moilanen and Wintle ${ }^{(63)}$ and Moilanen et al., ${ }^{(64)}$ where the info-gap approach was applied to identify an optimal reserve design and map core protection areas based on habitat suitability models. In our case, we applied the info-gap concept to find where our $S$. noctilio invasion risk map is 
"good enough" in the sense that it is robust to uncertainties in the model's parameters while also providing adequately stable risk estimates. We then used these results to evaluate the robustness of alternative designs of survey networks for monitoring $S$. noctilio to uncertainties about the level of invasion risk.

Instead of considering alternative decision scenarios, $\psi^{(38,65)}$, we first applied an info-gap approach to evaluate a set of $J$ geographical locations that constitute a risk map. In our case, each location (map cell) $j(j=1, \ldots, J)$ was characterized by a unique risk of invasion, $P_{j}$, and its standard deviation, $\sigma_{j}$. We analyzed each location separately and plotted the results as a map.

We adopted the described model of invasion as our "process model" (following info-gap terminology). Our corresponding model for uncertainty describes what is unknown about key assumptions in the process model, defined by a set of parameters, $x_{i}$. For this analysis, we considered six key model parameters (described in the preceding section) that were previously identified as having high impacts on risk estimates: ${ }^{(50)}$ local entry probability $\left(W_{z(t)}\right)$, population carrying capacity $(k)$, local probability of colonization $\left(p_{0}\right)$, maximum distance at which a new colony may become established $\left(d_{\max }\right)$, susceptibility of the host resource $\left(s_{\max }\right)$, and the total amount of host resource available at a given location $\left(g_{j(t)}\right)$. The nominal values for the selected parameters represent the extent of prior knowledge believed to be important about invasion. Thus, the model for uncertainty, $H(a)$, can be defined such that the values of $W_{z(t)}, K, p_{0}, d_{\max }, s_{\max }$, and $g_{j(t)}$ may deviate from their nominal values by an unknown fraction. Assuming a uniform-bound model, we defined several nested sets where each parameter deviated from its nominal value by a proportion $a$ or less (Equation (2); we assumed $w_{i}=1$ for simplicity but recognize that these values may be refined further if knowledge about the parameters' relative errors becomes available). Because the value of $a$ was unknown, we evaluated a set of nested intervals, $a \in$ $[0.1 ; 0.5]$.

To evaluate the "performance requirement," we calculated the expected utility metric, $V_{j}(x)$, based on two "process model" outputs: risk of invasion, $P_{j}(x)$, and its standard deviation, $\sigma_{j}(x)$, which represents a measure of output uncertainty. For each location $j$, the expected utility metric value was calculated as the squared Euclidean difference in both risk and standard deviation values between the estimates based on the nominal model parameters and the estimates for uncertainty horizon $a$ :

$$
\left.V_{j}(x)=-\left(\left[\left(P_{j}[x]-P_{j}[\bar{x}]\right)\right]^{2}+\left[\left(\sigma_{j}[x]\right)-\sigma_{j}[\bar{x}]\right)\right]^{2}\right),
$$

where $P_{j}(\bar{x})$ is the risk value at location $j$ based on the best (nominal) estimates of the model parameters, $\bar{x}$, and $\sigma_{j}(\bar{x})$ is the standard deviation of the risk value based on the nominal estimates. Similarly, $P_{j}(x)$ is the risk value at location $j$ evaluated with the model parameters $x$, and $\sigma_{j}(x)$ is the standard deviation of $P_{j}(x)$. Note that $\sigma_{j}(x)$ is not independent of $P_{j}(x)$ because the calculations used the same "process" model simulations for a specific realization of $x$. The utility metric value decreases when parametric uncertainties increase the risk value and/or its variation. In both cases, map cells with risk and standard deviation values matching the nominal scenario have the highest (least negative) utility values, approaching 0 . For each map location $j$, we defined its robustness as the maximum value of the uncertainty horizon, $\hat{a}_{j}$, that guaranteed the expected utility $V_{j}(x)$ to be no less than the critical threshold $V_{\min }$ :

$$
\hat{a}_{j}=\max \left\{a:\left(\min _{x \in H_{j}(a)} V_{j}(x)\right) \geq V_{\min }\right\} .
$$

Let $\mu(a)$ denote the inner minimum in Equation (5). The $\mu(a)$ is the inverse of the function $\hat{a}_{j}\left(V_{\min }\right)$, such that a plot of $\mu(a)$ versus $a$ is identical to a plot of $V_{\min }$ vs. $\hat{a}_{j}\left(V_{\min }\right)$. To calculate $\mu(a)$ we sampled the info-gap model of uncertainty, $H(a)$, at horizon of uncertainty $a$ to obtain parameter values $x_{m}$ over $M$ independent realizations, $m=1, \ldots, M$. We used these parameter values to perform $N$ individual model replications in order to estimate the probability and standard deviation of infestation, and the utility, $V_{j}\left(x_{m}\right)$, at location $j$. The calculation of $V_{j}\left(x_{m}\right)$ was repeated $M$ times. The lowest of the resulting $M$ estimates of utility was the approximate estimate of $\mu(a)$ :

$$
\begin{aligned}
& {\left[\underset{x_{m} \in H(a)}{x_{m}} \stackrel{N \text { reps }}{\Rightarrow} P_{j}\left(x_{m}\right), \sigma_{j}\left(x_{m}\right) \Rightarrow V_{j}\left(x_{m}\right)\right]_{m=1, \ldots, M}} \\
& \stackrel{M_{\text {reps }}}{\Rightarrow} \min _{m} V_{j}\left(x_{m}\right) \approx \mu(a) .
\end{aligned}
$$

Equation (6) is a numerical approximation to the definition of $\mu(a)$ as the inner minimum of the robustness. Based on the shape of the function $\min V_{j}(x)$ versus $a$, it was possible to outline the geographic areas where risk estimates were more (or less) 
"immune" to uncertainty in model assumptions at a specified horizon $a$.

Evaluation of the results requires understanding the importance of values of $V_{\min }$. Because the variation ranges of $P_{j}(x)$ and $\sigma_{j}(x)$ are known (i.e., $P_{j}(x) \in$ $[0 ; 1]$ and $\sigma_{j}(x) \in[0 ; \sim 0.5]$ for a binary distribution), the value of $V_{\min }$ can be associated with certain expected impacts of parametric uncertainties on the invasion risks. At $V_{\min }=-0.1$, there is an average impact of $\sim 10 \%$ change in $P_{j}(x)$ and $\sigma_{j}(x)$ values. This level compromises the numerical risk estimates but still allows qualitative comparison of what locations are more or less risky. At $V_{\min }$ below -0.25 , the validity of even the relative magnitudes of the risk estimates is dubious.

\subsection{Decision-Making Scenario}

We used the info-gap robustness function as a decision tool to select the pest survey network that is most immune to uncertainties about the pest. The values of the function $\min V_{j}(x)$ vs. $a$ (denoted as $\min V_{j}(x)[a]$ hereafter) calculated for individual survey locations were used to compare three alternative survey networks for $S$. noctilio, each consisting of approximately 1,000 points spread across the eastern United States. The networks were designed to monitor the mid-term expansion of $S$. noctilio (i.e., within a time horizon of 30 years). The geographical distribution of the survey points in each network follows the principles of a global sampling design for monitoring environmental phenomena. ${ }^{(66)}$ Fundamentally, the sampling design starts from a truncated icosahedron tessellation that divides the Earth's surface into 20 hexagon and 12 pentagon faces, with one hexagonal face centered on North America. The North American hexagon is defined by six vertices and a centroid, and this seven-point grid may be systematically decomposed (by a factor of 3 , 4,7 , or any product of these values) to create additional grid points. The decomposition factor can thus be used to appropriately increase the density of survey points within an area of concern (e.g., high-risk areas). The decomposition factor for a given region of interest also depends on the area of that region. Here we use the Coulston et al. ${ }^{(67)}$ approximation to calculate the decomposition factor, $\delta$, specifying the number of sample points in a region of interest:

$$
\delta=5783883\left(\frac{n_{u}}{A_{u}}\right),
$$

where $n_{u}$ is the desired number of sample points in a map region $u$, and $A_{u}$ is the total area (in kilometer square) of the region. As a result, the survey density and overall spatial configuration of the network both depend on the spatial arrangement of map regions, $u$.

In this study, we delineated the $U$ regions of interest from three alternative risk maps. The first variant employed the map of $P_{j}(\bar{x})$ values described in this study. The U.S. portion of this map was divided into four risk classes or map regions-high, moderate, low, and very low-defined by break points where $P_{j}(\bar{x})$ was equal to $0.75,0.25$, and 0.05 . The second example was based on a $S$. noctilio risk map developed by the USFS Forest Health Technology Enterprise Team (FHTET). ${ }^{(39)}$ The map portrays four risk classes, with high risks occurring in areas with abundant susceptible host (i.e., pine forests in the southeastern United States) and locations of potential pest introduction (such as marine ports and urban areas). The third variant used the map of $\sigma_{j}(\bar{x})$ values described in the present study and placed the highest survey densities in geographic areas exhibiting the highest levels of uncertainty in the risk estimates. The map was divided into four general classes representing high, moderate, low, and very low variability of risks, as defined by break points $\sigma_{j}(\bar{x})=0.4$, 0.2 , and 0.05 .

For all three examples, 500 survey points were placed in the high-risk class, 300 in moderate risk, 150 in low risk, and 50 in very low risk, for a total of 1,000 sample points spanning the eastern United States (Fig. 1). This example assumes at each higher level of risk, the decisionmaker desires a higher degree of confidence in survey efforts and a lower threshold for how extensive an infestation must be before it is detectable. The selection criteria for the optimum sample size and area are based on principles described in Coulston et al. ${ }^{(40)}$

We compared the networks' robustness to uncertainties about $S$. noctilio invasion using the functions $\min V_{j}(x)[a]$. For each survey network, the value of $\min V_{j}(x)$ was calculated from the values extracted from the corresponding map of the expected utility metric at the survey point locations.

\subsection{Simulation Scenarios}

The analysis proceeded as follows. First, we generated maps of $P_{j}(\bar{x})$ and $\sigma_{j}(\bar{x})$ using the nominal parameter values $\bar{x}_{i}$, and then simulated the scenarios depicting the nested uncertainty horizons $a$. We calculated maps of $\min V_{j}(x)$ versus $a$ for each scenario 
a)
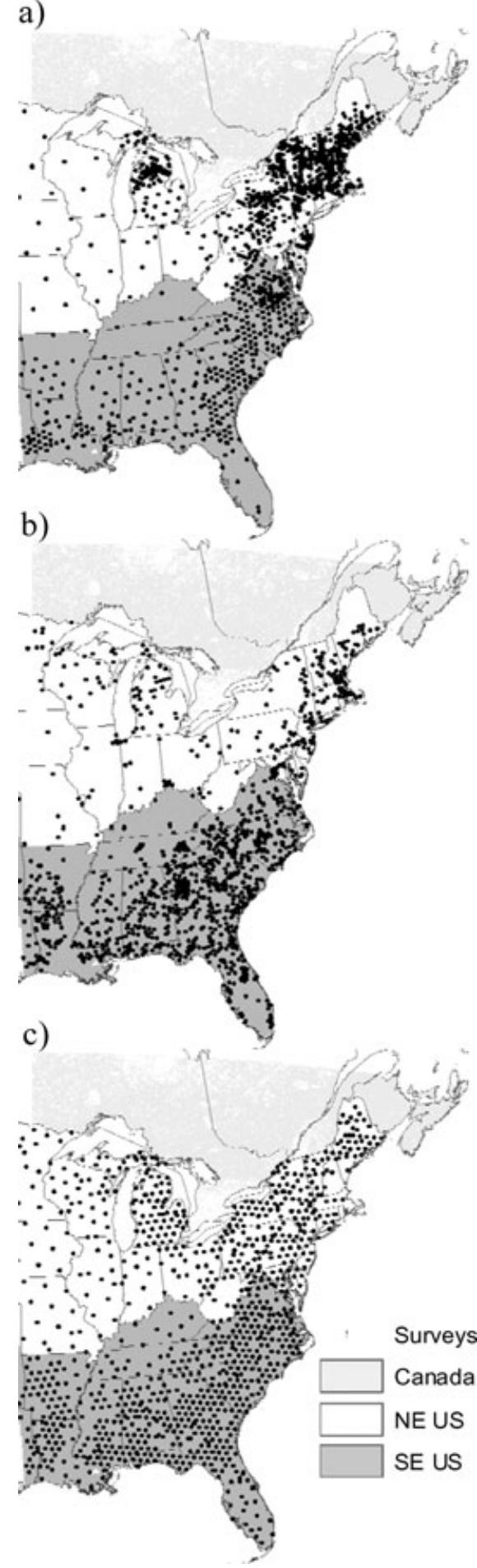

Fig. 1. Three alternative survey networks for monitoring $S$. noctilio: a) network based on the map of $P_{j}(\bar{x})$ values in the nominal scenario (this study); b) network based on a risk map constructed by the USDA Forest Service Forest Health Technology Enterprise Team (FHTET); ${ }^{\left({ }^{39}\right)} \mathrm{c}$ ) network based on the map of $\sigma_{j}(\bar{x})$ values in the nominal scenario (this study). based on a set of $M$ replications that were initialized with a unique set of randomized $x_{i}$ parameter values, varied independently within a uniform interval $\max [0, \pm \bar{x} a]$ (Equation (6)). Each of the $M$ replications required a minimum of $N$ independent model simulations to calculate the maps of $P_{j}(x)$ and $\sigma_{j}(x)$ and stabilize their spatial configuration. Consistent with the "high-risk" scenario in Yemshanov et al., ${ }^{(11)}$ $N$ was set to 300 replications.

To determine the minimum value of $M$ replications that stabilized the robustness function we used the sum of the squared differences in $\min V_{j}(x)[a]$ values between the trials using consecutively increasing numbers of replications:

$S_{M}=\sqrt{\sum_{j=1}^{J}\left[\min \left(V_{j}(x)[a]_{M+\Delta M}-\min \left(V_{j}(x)[a]_{M}\right)^{2}\right]\right.}$,

where $\min V_{j}(x)[a]_{M}$ and $\min V_{j}(x)[a]_{M+\Delta M}$ are the inverse robustness functions for a location $j$, at an uncertainty horizon $a$, based on $M$ and $M+\Delta M$ number of replications. Another informative convergence metric was the relative change in the map area occupied by the $\min V_{j}(x)[a]$ values above -0.2 and below -0.8 (i.e., representing high and low robustness to uncertainties):

$$
Y_{M}=\sqrt{\left(A_{M_{\max }}-A_{M}\right)^{2}},
$$

where $A_{M}$ is the area occupied by a given range of $\min V_{j}(x)[a]$ values based on $M$ number of replications and $A_{M \max }$ is the same area based on the maximum number of replications used in the analysis. Fig. 2 shows the number of replications required to stabilize the risk maps at the uncertainty horizons $a=0.1,0.3$, and 0.5 . In all cases, the robustness maps started to stabilize after 140 replications, so $M_{\max }$ was set to 300 . Overall, the analysis required undertaking $M \times N$ individual model simulations for each horizon of uncertainty, which represented a heavy computational task. The total number of model replications was thus limited by the available computing capacity, but included 270,000 individual model simulations for $a=0.1,0.3$, and 0.5 .

\section{RESULTS}

\subsection{Risks of Invasion and Their Variations}

Figs. 3a and 3b show, respectively, the risk of $S$. noctilio invasion, $P_{j}(\bar{x})$, and its standard deviation, $\sigma_{j}(\bar{x})$, for the scenario based on the nominal 

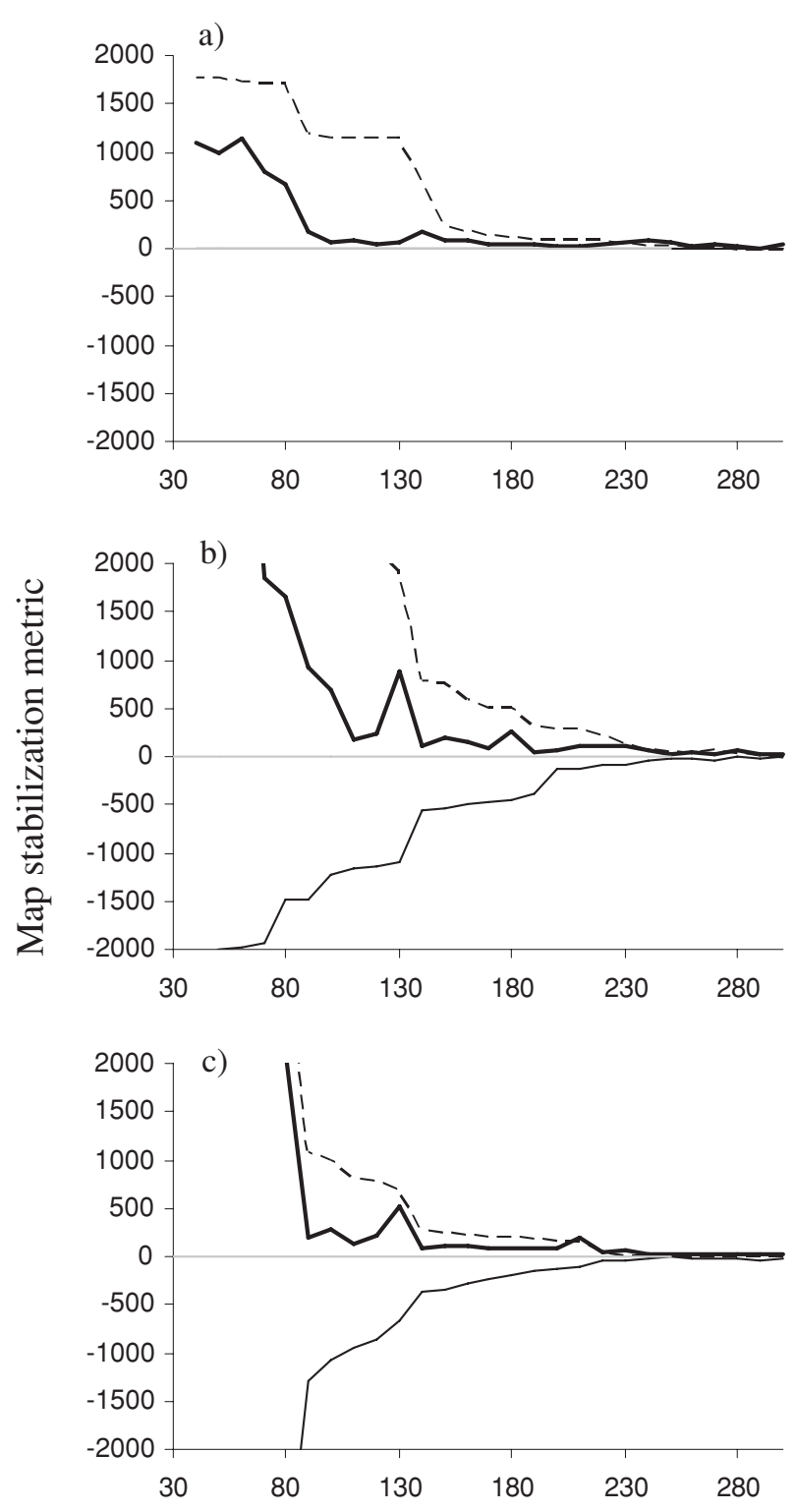

Number of replications, $M$

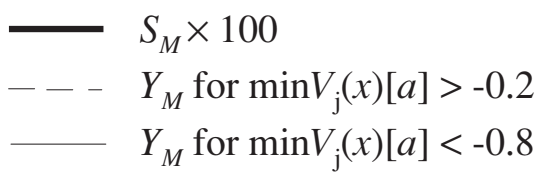

Fig. 2. Number of iterations, $M$, needed to stabilize the maps of robustness: a) $a=0.1$; b) $a=0.3$; c) $a=0.5$. Stabilization metrics: $Y_{M}$ shows relative change in the map area occupied by the $\min V_{j}(x)[a]$ values above -0.2 and below -0.8 (best and worst robustness to uncertainties) and also the $S_{M}$ values. The scenarios for the uncertainty horizons $a=0.1,0.3$, and 0.5 are shown. parameter values. The maps replicate a "high-risk" scenario described in Yemshanov et al. ${ }^{(11)}$ As expected, the areas to which the current $S$. noctilio infestations are expected to expand have very high risk values close to 1 . The risk map (Fig. 3a) shows two major regions of concern: (1) Ontario, Quebec, and the northeastern United States; and (2) an area extending south from Virginia, with a concentration of high-volume pine forests and high-capacity marine ports. The southeastern U.S. coast, with its abundant pine forests, shows moderate risks of invasion, mostly contributed by potential new entries at marine ports. The map of $\sigma_{j}(\bar{x})$ (Fig. 3b) displays similar geographical patterns. The highest variation in risk values is associated with the projected main front of invasion and areas of abundant host in the southeastern United States. Overall, $\sigma_{j}(\bar{x})$ is higher in areas with more heterogeneous host distribution (Fig. 3b).

Figs. $4 \mathrm{a}$ and $4 \mathrm{~b}$ show average absolute differences in $P_{j}(x)$ and $\sigma_{j}(x)$ values between the scenario using the nominal parameter values and the scenario for uncertainty horizon 0.5 (we present only one horizon here, as the scenarios using other values of $a$ revealed similar geographic patterns). Risk values remain stable only in close proximity to the currently infested extent (Fig. 4a) and in interior continental areas (Illinois, Iowa, and Missouri). The highest absolute differences are found on the southeastern U.S. coast and in the northern Lower Peninsula of Michigan as well as northern Canada. Nearly the entire study area shows differences in $\sigma_{j}(x)$ versus $\sigma_{j}(\bar{x})$ except currently infested regions and interior states. The largest deviations are found along the eastern U.S. coast near North Carolina and Virginia, in the southern Appalachian Mountains and in the western Great Lakes region (Fig. 4b). Another hotspot is shown in the boreal forests in Canada.

\subsection{Robustness Values}

Figs. 5a and 5b show maps of the expected utility values, $\min V_{j}(x)$ [a], for the uncertainty horizons $a=0.3$ and 0.5 , respectively. For the relatively strict utility threshold $V_{\min }=-0.1$ and the relatively high uncertainty horizon $a=0.5$, the risk map is characterized by high robustness to uncertainties within a $\sim 400 \mathrm{~km}$ radius of the first $S$. noctilio entry (i.e., the port of Oswego, NY) as well as in interior U.S. continental areas, namely, southern Iowa and northern Missouri (Fig. 5b, areas shaded in white). The regions with the lowest robustness to uncertainties, in 
a)

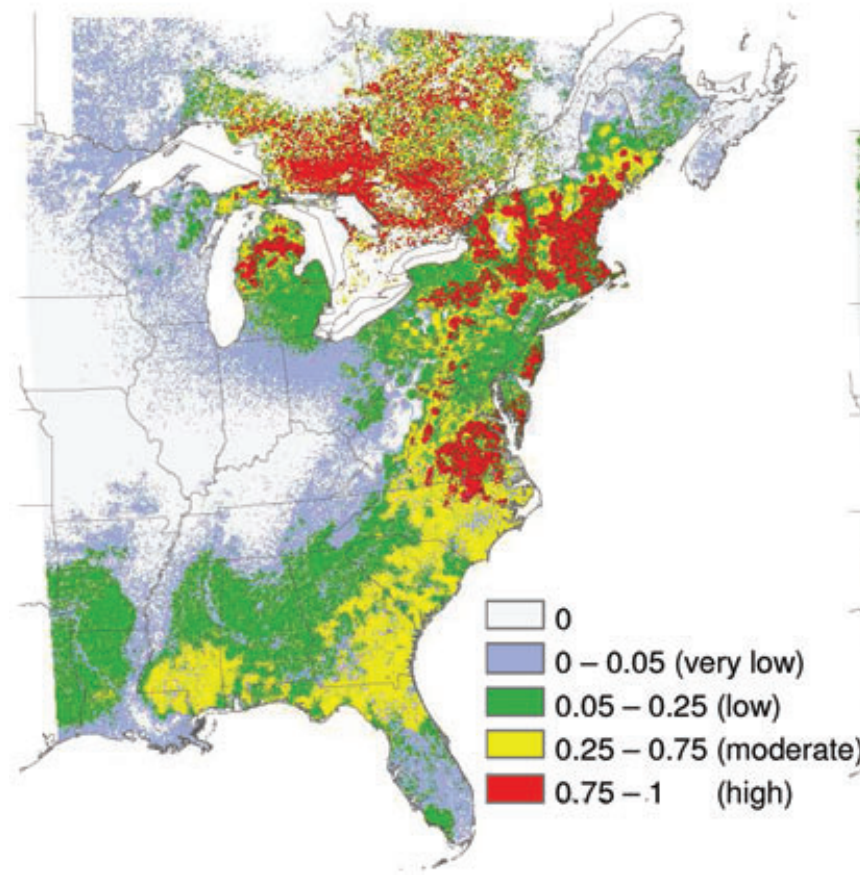

b)

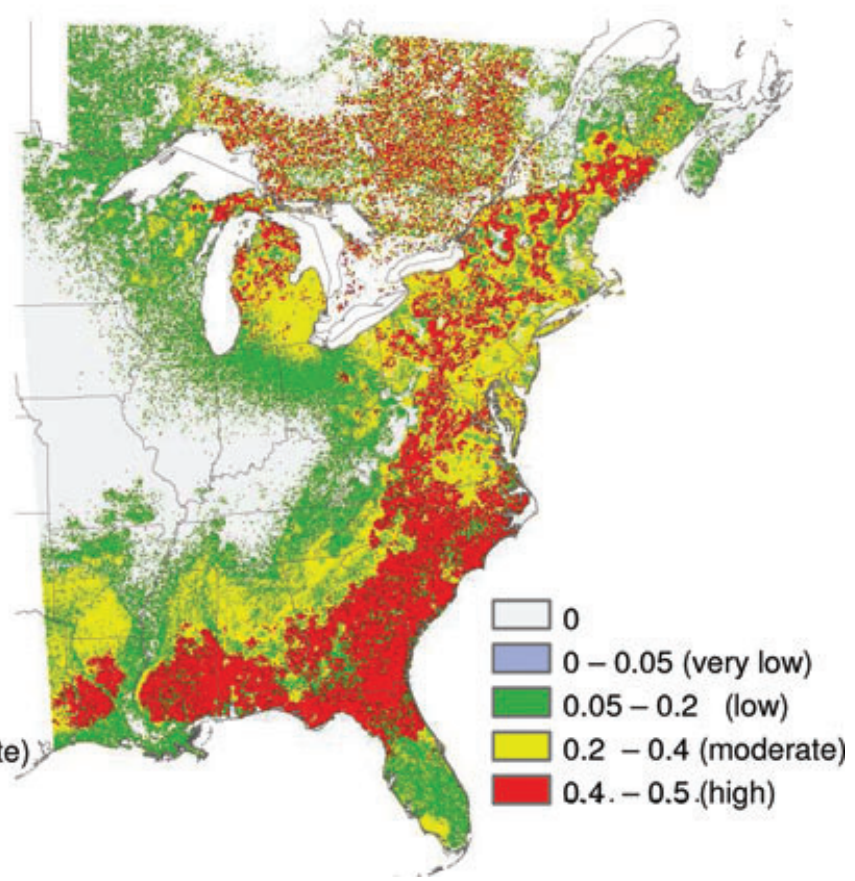

Fig. 3. Classified maps of $S$. noctilio infestation risks, $P_{j}(\bar{x})$, and their standard deviations, $\sigma_{j}(\bar{x})$, for the nominal scenario: a) $P_{j}(\bar{x})$; b) $\sigma_{j}(\bar{x})$.

a)

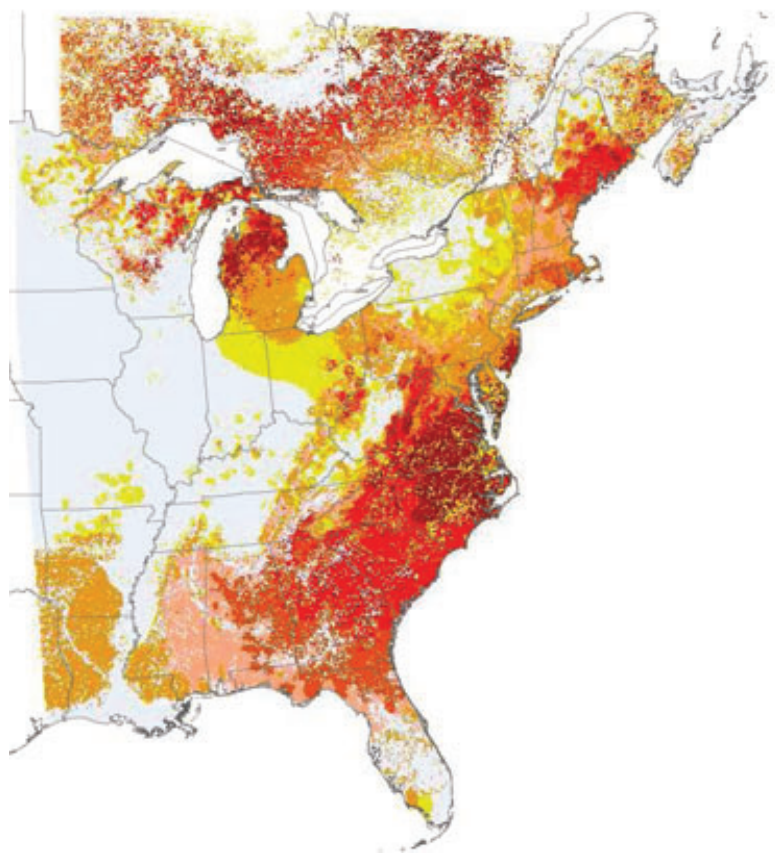

b)

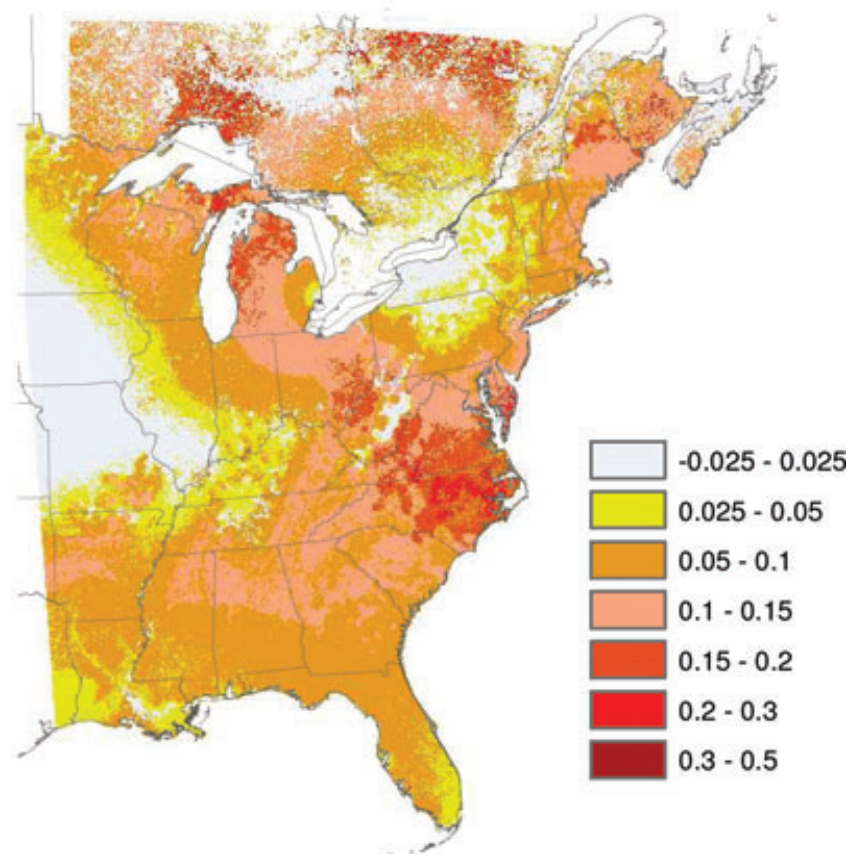

Fig. 4. Maps of absolute differences in $P_{j}(x)$ and $\sigma_{j}(x)$ values between the scenario for uncertainty horizon $a=0.5$ and the scenario based on the nominal parameter values: a) absolute differences in $P_{j}(x)$; b) absolute differences in $\sigma_{j}(\bar{x})$. 
a)

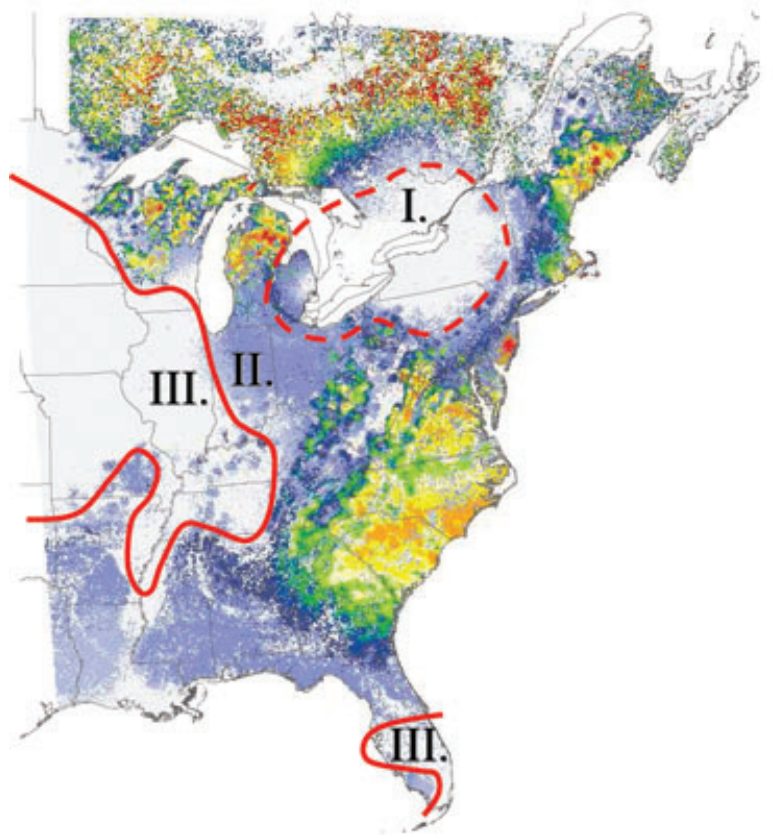

b)

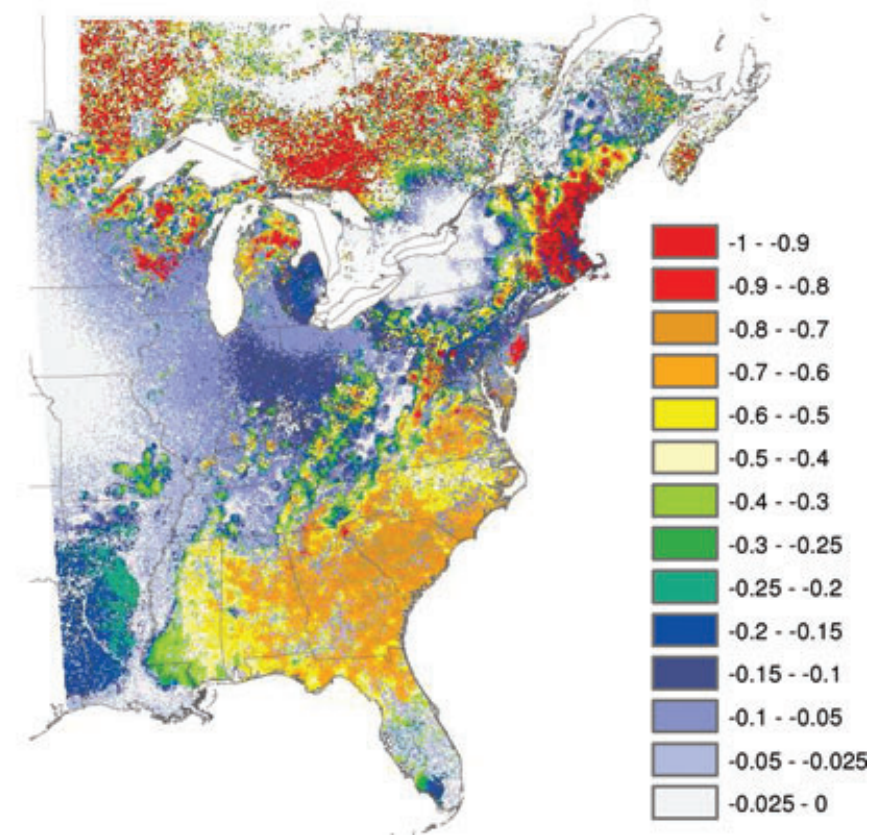

Fig. 5. Maps of the expected utility values, $\min V_{j}(x)$ vs. $a$, for the uncertainty horizons $a=0.3$ and 0.5 : a) $\min V_{j}(x)$ for $a=0.3$; b) $\min V_{j}(x)$ for $a=0.5$. I, II, III-broad spatial zones based on the robustness curves.

northern boreal Canada and the southeastern United States, were linked to areas with high concentrations of host species (pines). Northern pine forests in Canada and the upper U.S. Midwest have 20$30 \%$ lower robustness than the U.S. southeastern pine forests due to a more heterogeneous geographical pine distribution and closer proximity to existing $S$. noctilio infestations (Fig. 5b). At the lower uncertainty horizon, $a=0.3$ (Fig. 5a), the risk map remains robust in most areas except the southeastern United States and northern Canada, as well as portions of the U.S. Atlantic coast.

Expectations regarding the confidence in risk estimates also change the robust portion of the map. Fig. 6 shows the percentage of the $390 \mathrm{M} \mathrm{km}^{2}$ map area that is robust to uncertainties under the expectations of $\min V_{j}(x)=-0.1,-0.25$, and -0.5 . Specifically, the horizontal axis is the value of the robustness, $a$, and the vertical axis is the percentage area with at least this level of robustness. In all cases, most of the map area is robust to uncertainties for $a=0.1$. At higher $a$ values, we see differentiation between regions, with fewer and fewer regions remaining robust to uncertainties. Furthermore, the fall-off in percentage of robust area is more pronounced for more demanding aspirations (i.e., for the higher util- ity threshold values, particularly $\min V_{j}(x)=-0.1$ ). Percentages of robust map area for three distinct geographic regions-eastern Canada, the northeastern United States, and southeastern United States-are also shown in Fig. 6. The Canadian portion of the study area appears the most vulnerable to uncertainties. For the higher aspirations of $\min V_{j}(x)=-0.1$ and -0.25 , the percentage of the map area that has robustness of at least $a=0.3$ declines to $52 \%$ and $69 \%$, respectively, relative to the nominal scenario. In contrast, these reductions amount to only $83 \%$ and $91 \%$ in the northeastern United States, and to $69 \%$ and $80 \%$ of map area in the southeastern United States.

\subsection{Robustness of the Pest's Survey Networks to Uncertainties}

We compare the three alternative survey networks for $S$. noctilio using the $V_{\min }$ versus $\hat{a}$ functions calculated at individual survey locations. We sample the maps of $\min V_{j}(x)[a]$ at the locations, $u$, that constitute the network of pest surveys, $u=$ $1, \ldots, U$ (Fig. 1). Fig. 7 shows the mean values of the robustness curves for the northeastern and southeastern United States as well as the entire eastern 
Fig. 6. Percentage of map area remaining robust at a given uncertainty horizon $a$ : a) eastern North America; b) northeastern United States; c) eastern Canada; d) southeastern United States. Three aspirations of the expected utility threshold are shown, $\min V_{j}(x)=-0.1$, -0.25 , and -0.5 . a)

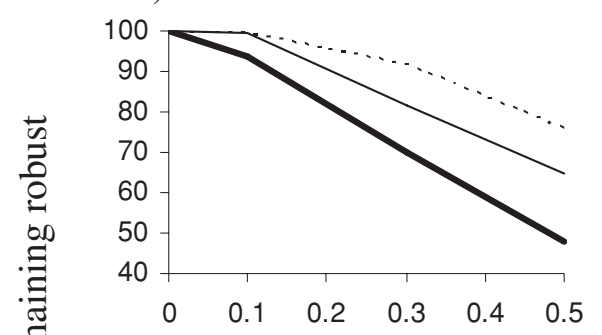

c)

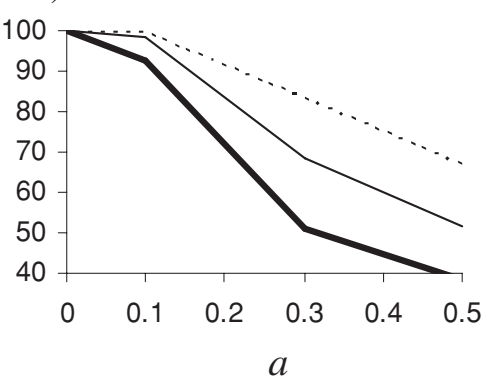

b)

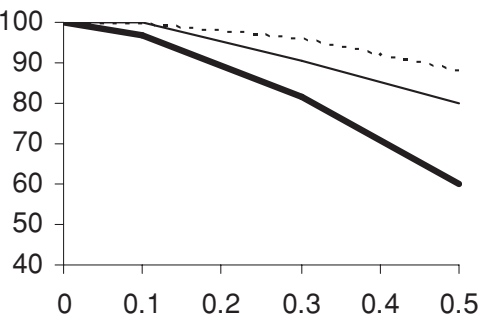

d)

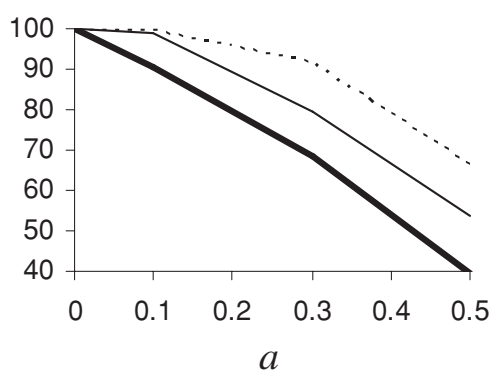
$\min V_{j}(x):=-0.1 \quad-0.25 \quad-\cdots-0.5$

United States. The robustness curves are useful in understanding the dependency between the quality of the outcome (expressed by $V_{\min }$ ) and the confidence in obtaining that outcome (expressed by the robustness to uncertainty, $\hat{a}$ ), that is, $V_{\min }$ versus $\hat{a}$. This dependency is implicit in the declining slope of these robustness curves. Fig. 7 shows that the survey network based on the map of $\sigma_{j}(\bar{x})$ values from this study is the most robust to uncertainties overall (decision curve 3 in Fig. 7). The network based on the FHTET risk map exhibits robustness similar to the $\sigma_{j}(\bar{x})$ case in the southeastern United States, and even slightly higher when expectations regarding the quality of risk predictions are low (i.e., $\hat{a}=$ 0.5 , Fig. 7c)). This is because the majority of survey points in both networks are placed within, or in close proximity to the susceptible host resource in the southeastern United States (where the uncertainties about invasion are the highest; see Fig. 3b)). The network based on the maps of $P_{j}(\bar{x})$ values shows the lowest robustness across all three regions (Fig. 7a)), especially in the southeast where it is significantly less robust than the networks based on the FHTET risk map and $\sigma_{j}(\bar{x})$. The robustness premium can be substantial. For instance, in the northeastern United States, the network based on $P_{j}(\bar{x})$ values shows robustness of about $30 \%(0.3)$ at $V_{\min }=-0.2$, while the robustness of the network based on the $\sigma_{j}(\bar{x})$ values is about $45 \%(0.45)$. In other words, the latter net- work can tolerate $15 \%$ more uncertainty in the critical parameters without violating the performance requirement (i.e., the utility value, $V_{\min }$, no less than -0.2 ).

Fig. 7c) shows an example of preference reversal in the southeastern United States: the network based on the FHTET map is slightly more robust (and hence preferred) at expectations of low-quality knowledge about the invasion (i.e., $a \geq 0.5$ ), while the network based on $\sigma_{j}(\bar{x})$ is a better choice given expectations of higher-quality information about the pest of interest. The preference reversal is very minor; however, it shows up consistently after $M>\sim 80$ model replications (Equation (6)). In the U.S. Northeast, the network based on $\sigma_{j}(\bar{x})$ is clearly a better choice than the others, especially under the assumption of poor-quality knowledge about the invasion (i.e., $a \geq 0.5$ ).

\section{DISCUSSION}

The approach presented here evaluates the robustness of pest risk maps to uncertainties in key assumptions about an invading organism. The incorporation of the robustness concept becomes an important decision-making component as it may lead to more risk-aware decisions in implementing pest management and mitigation activities. In fact, selecting the survey network that is most stable in the 


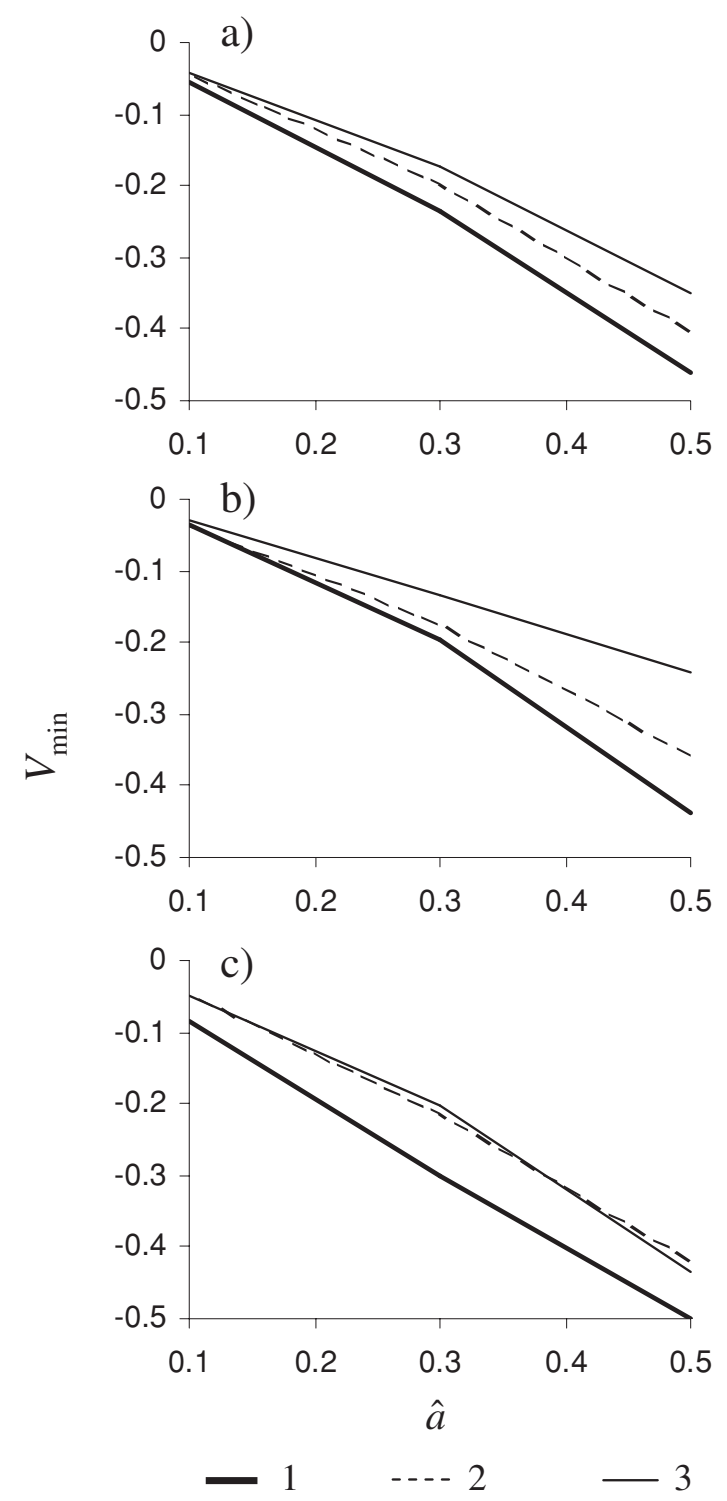

Fig. 7. Robustness, $V_{\min }$ versus $\hat{a}$, of the three survey networks to uncertainties regarding the $S$. noctilio invasion: a) eastern United States; b) northeastern United States; c) southeastern United States. 1 network based on the map of $P_{j}(\bar{x})$ values in the nominal scenario for this study; 2 network based on the FHTET risk map; ${ }^{(39)} 3$ network based on the map of $\sigma_{j}(\bar{x})$ values in the nominal scenario.

face of "unknowns" about a new pest also offers cost advantages, especially when the predicted extent of the outbreak is potentially large and the consequences are possibly grave. This is an important practical consideration given that decisions about monitoring and regulation are often made under the pressure of limited time and severe lack of information about the new invasive pest.
From a decision theory perspective, ${ }^{(68)}$ risk mapping represents an example of decision making under severe uncertainty. Risk assessments under these circumstances typically reflect a decisionmaker's ignorance regarding the probability of an undesired event, which tends to lead toward a quite restricted characterization of the relative likelihood of the event (i.e., simply trying to ascertain if there is any risk of invasion). In an ideal situation, assessments would determine the precise probability of an undesirable event (i.e., would generate quantitative risk values), but the case of severe uncertainty leaves little opportunity to do this because the information that is available about a new invader is generally too vague to do accurate probabilistic assessments. Our approach shows how to address that issue in a more systematic and repeatable manner, and thus can be viewed as a valuable decision support tool in the case of a poorly understood new invader.

\subsection{Geographical Patterns of the Robustness to Uncertainty}

Maps of the expected utility metric illustrate where risk estimates are most robust to uncertainty. Boreal and subboreal Canada, and the portion of the northeastern United States proximal to the current $S$. noctilio outbreak, exhibit the lowest robustness. Pine regions in the southeastern United States also have low robustness, while interior continental areas in the central United States exhibit general robustness to uncertainty. This, however, is only because the underlying risk model allows limited new entries at major marine ports. Interior areas would be less robust to uncertainty if the risk model allowed for the possibility of new entries at inland urban locations.

Importantly, the maps show a consistent $20-30 \%$ difference in robustness between the northern boreal and southern pine forests. This is clearly the result of closer proximity to the existing S. noctilio outbreak and higher spatial heterogeneity of northern pine forests (where mixed conifer-hardwood stands are typical).

On a larger scale, the results reveal systematic patterns of how uncertainties in risk model parameters change the reliability of the risk map. These patterns can be aggregated in three broad zones with distinct robustness curves, $V_{\min }$ versus $\hat{a}$. The first zone (shown as region I in Fig. 5a)) exhibits good robustness to uncertainties with relatively high $\hat{a}$ values for the entire range of $V_{\min }$, as well as high invasion risks with low variability or output uncertainty (the areas 
in Fig. 5 proximal to the current $S$. noctilio infestations). Essentially, this zone represents the "known knowns" with respect to an invasion and demarcates where risk estimates are defined with confidence.

As a rule, the second zone (region II in Fig. 5a)) includes the projected leading edge or front of invasion at the forecast time horizon and is characterized by moderate risks and high variability of the robustness to uncertainty. The region includes the bulk of pine forests in the southeastern and northeastern United States and eastern Canada. This is a zone of "known unknowns," where current knowledge about the invading organism suggests a possibility of invasion but is not sufficiently detailed to predict exactly where and when invasion will occur.

The third region (depicted as zone III in Fig. 5a)) usually encompasses areas beyond the projected invasion front. This zone is characterized by relatively low risks with low variability and apparently very good robustness to uncertainties (e.g., the area remaining robust in the United States west of Iowa, Fig. 5). However, this zone may also include conditions where the current knowledge about an invader is too limited to quantify future risks properly (e.g., lack of data about the potential introductions at inland sites in our case). Interpreting these regions of "unknown unknowns" requires extreme caution because assessments made under severe lack of knowledge about invasion often display low risks and thus may promote a false confidence.

Overall the geographic variation of the robustness to uncertainties can be explained by the interaction of three main drivers of the invasion: the geographic distribution of a susceptible host resource, anticipated spatial extent, and the rate of spread of the invasion. For example, the southern U.S. coast shows moderate risks of invasion, yet this area shows very low robustness to uncertainties due to abundant susceptible host. Similarly, northern Canada and the portion of the upper Midwest region that lies west of the Great Lakes are characterized by moderate risks of infestation, but exhibit the worst robustness to uncertainty due to close proximity to existing infestations.

\subsection{Info-Gap Theory and the Design of the Pest Survey Networks}

The info-gap approach seems useful for the coordination of monitoring efforts during early stages of an invasion, when knowledge about a pest is scarce. Regarding the broad invasion zones outlined in the previous section, the "known knowns" zone does not require a dense survey network because of high confidence in the risk estimates. The zone of "known unknowns" may require the highest density of observations (especially in the areas with the lowest robustness to uncertainties) because this is where the reduction of uncertainty will have the highest impact on the reliability of risk estimates. The zone of "unknown unknowns" also calls for a certain minimum survey density to test whether the "low-risk" designation is actually the result of severe lack of knowledge about the pest. A comparison of the alternative survey networks presented here illustrates how confidence in predicting invasion risks depends on accounting for uncertainties in the knowledge regarding an invasive pest. In the optimal network design, it seems that the density of survey observations should correlate with the estimated uncertainties in the risk predictions, rather than the actual risk values. In our example, the network based on the map of $\sigma_{j}(\bar{x})$ appears most robust to poor knowledge regarding S. noctilio.

Interestingly, the network based on the FHTET risk map shows high robustness despite the fact that uncertainties in the underlying assumptions about $S$. noctilio were not considered explicitly. ${ }^{39}$ Both the FHTET and $\sigma_{j}(\bar{x})$ maps identify regions of pine forests in the southeastern United States as primary areas of concern. This suggests that uncertainties may have been included implicitly via ranking of the component variables in the FHTET maps. The infogap concept provides an alternative and perhaps better way of incorporating these uncertainties in the design of pest monitoring and mitigation activities.

\subsection{Practical Application Issues}

While our results illustrate the basic concept, practical application of the info-gap approach in pest risk mapping will require resolution of several issues. First is the formulation of an appropriate expected utility metric. Our current analysis weighted $P_{j}(x)$ and $\sigma_{j}(x)$ equally, which thus makes any changes in risk values twice as influential as changes in their variation (simply because $P_{j}(x)$ ranges between 0 and 1 and $\sigma_{j}(x)$ between 0 and $\left.\sim 0.5\right)$. Alternatively, these weights may be influenced by the decisionmaker's behavior. For instance, a risk-averse decision style might assume a higher importance for $\sigma_{j}(x)$ than $P_{j}(x)$. The expected utility metric may also incorporate other considerations deemed important, for example, the distance to existing infestations and/or the 
costs of the failure to detect the pest in certain geographic areas (e.g., regions in the southern United States with high-volume pine forests).

Second, the study only considers unbounded parametric uncertainties with respect to the underlying invasion risk model. We have not evaluated other uncertainties associated with the quality of geographical information or the formulation of the risk model. Assessing model uncertainty represents a challenge because alternative models often have different parameter spaces, for example, a relatively simple traveling wave model ${ }^{(56)}$ versus a complex population model. ${ }^{(69)}$ Potentially, this issue can be addressed with the idea of Wald's worst-case scenario ${ }^{(70)}$ or ensemble analysis. ${ }^{(33,34)}$ The latter approach, however, has been criticized for its inability to identify a "correct" model. ${ }^{(31)}$ In addition, under severe uncertainty it may not be possible to reliably identify a worst case.

The third big concern is the appropriateness of the simulation risk model as formulated. We are currently exploring alternate representations of $S$. noctilio entry in the context of human-mediated dispersal. This includes the simulation of long-distance spread via a freight transportation network and subsequent accidental entries near urban areas or distribution centers. On a temporal scale, entry potential will also require a more detailed portrayal of future impacts of the FAO-IPPC ${ }^{(54)}$ phytosanitary rules and better understanding of which commodities and cargoes are likely to harbor the pest.

\section{CONCLUSIONS}

Decisionmakers routinely respond to invasive pest threats under circumstances where relatively little is known about a new invader. Despite this severe uncertainty, they face the problems of clarifying the likelihood and impact of new outbreaks, planning control strategies, and subsequently estimating their cost effectiveness to provide justification for their choices. Risk maps represent an important decision support tool but they often fail to represent their intrinsic uncertainties clearly and meaningfully. In this article, we have used an infogap approach to assess the robustness of pest risk maps to uncertainties about the pest and applied the results to inform the selection of a survey network for pest monitoring. The analysis uses a simulation model to generate the risk map of invasion and evaluates how uncertainties change the mapped risk estimates and their variation. The results show the de- pendence between the acceptable horizon of uncertainty about a new invader and the reliability of the risk map. Perhaps our most interesting finding is that robustness to uncertainty varies systematically between distinct geographic regions that will require different strategies for pest monitoring and other management efforts. This may provide decisionmakers with a better understanding of the reliability of risk maps and allow them to explicitly account for uncertainties and knowledge gaps in their decision process. Overall, the approach is fairly generic and can be applied to other invasive threats and quantitative risk models.

\section{ACKNOWLEDGMENTS}

The authors extend their gratitude and thanks to Anne Bostelaar and Daniel Sdao (Natural Resources Canada, Canadian Forest Service) and Kurt Riitters (USDA Forest Service, Southern Research Station) for technical support with large-scale numeric simulations. The participation of Denys Yemshanov was supported by Natural Resources Canada, Canadian Forest Service. The participation of Frank Koch was supported by Research Joint Venture Agreements \#06-JV-11330146-123 and \#08-JV-11330146-078 between the USDA Forest Service, Southern Research Station, Asheville, NC and North Carolina State University.

\section{REFERENCES}

1. Andersen MC, Adams H, Hope B, Powell M. Risk assessment for invasive species. Risk Analysis, 2004; 24(4):787-793.

2. Baker R, Cannon R, Bartlett P, Barker I. Novel strategies for assessing and managing the risks posed by invasive alien species to global crop production and biodiversity. Annals of Applied Biology, 2005; 146:177-191.

3. Stohlgren TJ, Schnase JL. Risk analysis for biological hazards: What we need to know about invasive species. Risk Analysis, 2006; 26(1):163-173.

4. Magarey RD, Fowler GA, Borchert DM, Sutton TB, ColungaGarcia M, Simpson JA. NAPPFAST: An Internet system for the weather-based mapping of plant pathogens. Plant Disease, 2007; 91:336-345.

5. Elith J, Graham CH, Anderson RP, Dudik M, Ferrier S, Guisan A, Hijmans RJ, Huettmann F, Leathwick JR, Lehmann A, Li J, Lohmann LG, Loiselle BA, Manion G, Moritz C, Nakamura M, Nakazawa Y, Overton JM, Peterson AT, Phillips SJ, Richardson K, Scachetti-Pereira R, Schapire RE, Soberon J, Williams S, Wisz MS, Zimmermann NE. Novel methods improve prediction of species' distributions from occurrence data. Ecography, 2006; 29:129-151.

6. Keith DA, Akçakaya HR, Thuiller W, Midgley GF, Pearson RG, Phillips SJ, Regan HM, Araújo MB, Rebelo TG. Predicting extinction risks under climate change: Coupling stochastic population models with dynamic bioclimatic habitat models. Biology Letters, 2008; 4:560-563. 
7. Rafoss T. Spatial stochastic simulation offers potential as a quantitative method for pest risk analysis. Risk Analysis, 2003; 23(4):651-661.

8. Bartell SM, Nair SK. Establishment risks for invasive species. Risk Analysis, 2003; 24(4):833-845.

9. Orlandini S, Dalla Marta A, Martinelli L. Using simulation modelling as a policy option in coping with agrometeorological risks and uncertainties. Pp. 463-476 in Sivakumar MVK, Motha RP (eds). Managing Weather and Climate Risks in Agriculture. Berlin, Heidelberg: Springer, 2007.

10. Yemshanov D, McKenney DW, de Groot P, Haugen D, Sidders D, Joss B. A bioeconomic approach to assess the impact of a nonnative invasive insect on timber supply and harvests: A case study with Sirex noctilio in eastern Canada. Canadian Journal of Forest Research, 2009; 39(1):154-168.

11. Yemshanov D, Koch FH, McKenney DW, Downing MC, Sapio FJ. Mapping invasive species risks with stochastic models: A cross-border U.S.-Canada application for Sirex noctilio Fabricius. Risk Analysis, 2009; 29(6):868-884.

12. Kot M, Lewis MA, Van Den Driessche P. Dispersal data and the spread of invading organisms. Ecology, 1996; 77:20272042.

13. Shigesada N, Kawasaki K. Biological Invasions: Theory and Practice. Oxford: Oxford University Press, 1997.

14. Hastings A, Cuddington K, Davies KF, Dugaw CJ, Elmendorf S, Freestone A, Harrison S, Holland M, Lambrinos J, Malvadkar V, Melbourne BA, Moore K, Taylor C, Thompson D. The spatial spread of invasions: New developments in theory and evidence. Ecology Letters, 2005; 8:91-101.

15. Herborg L-M, Jerde CL, Lodge DM, Ruiz GM, MacIsaac HJ. Predicting invasion risk using measures of introduction effort and environmental niche models. Ecological Applications, 2007; 17(3):663-674.

16. Neubert MG, Caswell H. Demography and dispersal: Calculation and sensitivity analysis of invasion speed for structured populations. Ecology, 2000; 81:1613-1628.

17. Liebhold AM, Tobin PC. Population ecology of insect invasions and their management. Annual Review of Entomology, 2008; 53:387-408.

18. Tobin PC, Blackburn LM. (eds.) Slow the Spread: A National Program to Manage the Gypsy Moth. USDA Forest Service, Gen. Tech. Rep. NRS-6; Newton Square, PA: Northern Res. Stn., 2007.

19. Turner MG, Collins SL, Lugo AL, Magnuson JJ, Rupp TS, Swanson FJ. Disturbance dynamics and ecological response: The contribution of long-term ecological research. BioScience, 2003; 53(1):46-56.

20. McKenney DW, Hopkin AA, Campbell KL, Mackey BG, Foottit RG. Opportunities for improved risk assessments of exotic species in Canada using bioclimatic mapping. Environmental Monitoring and Assessment, 2003; 88:445-461.

21. USDA (U.S. Department of Agriculture). National Strategy and Implementation Plan for Invasive Species Management. USDA Forest Service, Pub. FS-805. Washington, DC, 2004. Available at: http://www.fs.fed.us/invasivespecies/ documents/Final_National_Strategy_100804.pdf. Accessed April 30, 2009.

22. USDA (U.S. Department of Agriculture). Addressing the Threat of Invasive Species to Our Nation's Forests in an International Context, 2006. Available at: http://www.fs.fed.us/ global/aboutus/policy/tt/reports/4threats/invasive_species.pdf. Accessed March 13, 2009.

23. Holling CS. (ed). Adaptive Environmental Assessment and Management. Chichester, UK: Wiley, 1978.

24. Morgan MG, Henrion M. Uncertainty: A Guide to Dealing with Uncertainty in Quantitative Risk and Policy Analysis. New York: Cambridge University Press, 1990.

25. Elith J, Burgman MA, Regan HM. Mapping epistemic uncertainties and vague concepts in predictions of species distribution. Ecological Modelling, 2002; 157:313-329.
26. Regan HM, Colyvan M, Burgman MA. A taxonomy and treatment of uncertainty for ecology and conservation biology. Ecological Applications, 2002; 12(2):618-628.

27. Swartzman GL, Kaluzny SP. Ecological Simulation Primer. New York: MacMillan Publ. Co., 1987.

28. Walley P. Statistical Reasoning with Imprecise Probabilities. London, UK: Chapman and Hall, 1991.

29. Henderson-Sellers B, Henderson-Sellers A. Sensitivity evaluation of environmental models using fractional factorial experimentation. Ecological Modelling, 1996; 86:291-295.

30. Ben-Haim Y. Info-Gap Decision Theory: Decisions Under Severe Uncertainty, 2nd ed. Oxford, UK: Academic Press, 2006.

31. Worner SP, Gevrey M. Modelling global insect pest species assemblages to determine risk of invasion. Journal of Applied Ecology, 2006; 43(5):858-867.

32. Demeritt D, Cloke H, Pappenberger F, Theilen J, Bartholmes $\mathrm{J}$, Ramos M-H. Ensemble predictions and perceptions of risks, uncertainty, and error in flood forecasting. Environmental Hazards, 2007; 7(2):115-127.

33. Buizza R, Houtekamer PL, Coth Z, Pellerin G, Wei M, Zhu Y. Assessment of the status of global ensemble prediction. Monthly Weather Review, 2003; 133:1076-1097.

34. Araújo MB, New M. Ensemble forecasting of species distributions. Trends in Ecology and Evolution, 2007; 22:42-47.

35. Keeney RL, Raiffa H. Decisions with Multiple Objectives. New York: Wiley, 1976.

36. von Winterfeldt D, Edwards W. Decision Analysis and Behavioral Research. London: Cambridge University Press, 1986.

37. Stewart TJ, A critical survey on the status of multiple criteria decision making theory and practice. Omega, 1992; 20:569586.

38. Regan HM, Ben-Haim Y, Langford B, Wilson WG, Lundberg $\mathrm{P}$, Andelman AJ, Burgman MA. Robust decision-making under severe uncertainty for conservation management. Ecological Applications, 2005; 15(4):1471-1477.

39. FHTET (U.S. Department of Agriculture, Forest Health Technology Enterprise Team). Sirex Woodwasp Risk Maps and Documentation. 2007. Available at: http://www.fs.fed. us/foresthealth/technology/invasives_sirexnoctilio_riskmaps. shtml. Accessed January 14, 2009.

40. Coulston JW, Koch FH, Smith WD, Sapio FJ. Invasive forest pest surveillance: Survey development and reliability. Canadian Journal of Forest Research, 2008; 38:2422-2433.

41. Foxcroft LC, Rouget M, Richardson DM. Risk assessment of riparian plant invasions into protected areas. Conservation Biology, 2007; 21:412-421.

42. Hoebeke RE, Haugen DA, Haack RA. Sirex noctilio: Discovery of a Palearctic siricid woodwasp in New York. Newslett. Mich. Entomol. Soc., 2005; 50:24-25.

43. De Groot P, Nystrom K, Scarr T. Discovery of Sirex noctilio (Hymenoptera: Siricidae) in Ontario, Canada. Great Lakes Entomologist, 2006; 39:49-53.

44. Carnegie AJ, Matsuki M, Haugen DA, Hurley BP, Ahumada R, Klasmer P, Sun J, Iede ET. Predicting the potential distribution of Sirex noctilio (Hymenoptera: Siricidae), a significant exotic pest of Pinus plantations. Annals of Forest Science, 2006; 63:119-128.

45. Haugen DA. Sirex noctilio. In Exotic Forest Pest Information System for North America. North American Forest Commission, 2006. Available at: http://spfnic.fs.fed.us/exfor/ data/pestreports.cfm?pestidval=33\&langdisplay=english. Accessed January 10, 2009.

46. Borchert D, Fowler G, Jackson L. Organism Pest Risk Analysis: Risks to the Conterminous United States Associated with the Woodwasp, Sirex noctilio Fabricius, and the Symbiotic Fungus, Amylostereum areolatum, (Fries: Fries) Boidin. USDA-APHIS-PPQ-CPHST-PERAL. Rev.1., 2007. Available at: http://www.aphis.usda.gov/plant_health/plant_pest_ info/sirex/downloads/sirex-pra.pdf. Accessed March 10, 2009. 
47. Corley JC, Villacide JM, Bruzzone OA. Spatial dynamics of a Sirex noctilio woodwasp population within a pine plantation in Patagonia, Argentina. Entomologia Experimentalis et Applicata, 2007; 125:231-236.

48. Haugen DA, Hoebeke ER. Pest Alert Sirex woodwasp-Sirex noctilio F. (Hymenoptera: Siricidae). USDA Forest Service NA-PR-07-05, 2005.

49. Hurley BP, Slippers B, Wingfield MJ. A comparison of the control results for the alien invasive woodwasp, Sirex noctilio, in the southern hemisphere. Agricultural and Forest Entomology, 2007; 9:159-171.

50. Koch F, Yemshanov D, McKenney D, Smith W. Evaluating critical uncertainty thresholds in a spatial model of forest pest invasion risk. Risk Analysis, to appear. DOI: 10.1111/j.15396924.2009.01251.x.

51. APHIS (U.S. Department of Agriculture, Animal and Plant Health Inspection Service and Forest Service APHIS). Sirex noctilio Delimiting Survey Eastern Region. 2007. Available at: http://www.aphis.usda.gov/plant_health/plant_pest_info/sirex/ downloads/delimiting_survey_9-07.pdf. Accessed January 10, 2009.

52. Costello C, McAusland C. Protectionism, trade, and measures of damage from exotic species introductions. American Journal of Agricultural Economics, 2003; 85(4):964-975.

53. Levine JM, D'Antonio CM. Forecasting biological invasions with increasing international trade. Conservation Biology, 2003; 17(1):322-326.

54. FAO-IPPC. Guidelines for regulating wood packaging material in international trade. ISPM No.15 (2002). Pp. 174-183 in International Standards for Phytosanitary Measures, Rome: FAO-IPPC, 2006.

55. FHTET (U.S. Department of Agriculture, Forest Service Forest Health Technology Enterprise Team). Sirex WoodwaspSirex noctilio. Commodities likely associated with Sirex noctilio. 2007. Available at: http://www.fs.fed.us/foresthealth/ technology/pdfs/assoc_commodities_sirex.pdf. Accessed March 21, 2008.

56. Sharov AA, Liebhold AM. Model of slowing the spread of gypsy moth (Lepidoptera: Lymantriidae) with a barrier zone. Ecological Applications, 1998; 8(4):1170-1179.

57. FHTET (U.S. Department of Agriculture, Forest Service Forest Health Technology Enterprise Team). Sirex Woodwasp Sirex noctilio. Host species susceptibility. 2007. Available at: http://www.fs.fed.us/foresthealth/technology/pdfs/host_species _susceptibility.pdf. Accessed March 21, 2008.

58. Gillis MD. Canada's national forest inventory, responding to current information needs. Environmental Monitoring and Assessment, 2001; 67:121-129.
59. Reams GA, Smith WD, Hansen MH, Bechtold WA, Roesch FA, Moisen GG. The Forest Inventory and Analysis sampling frame. Pp. 11-26 in Bechtold WA, Patterson PL (eds). The Enhanced Forest Inventory and Analysis Program-National Sampling Design and Estimation Procedures. Asheville, NC: USDA Forest Service, Southern Research Station, 2005.

60. USDA FS (USDA Forest Service). Forest Inventory and Analysis Database: Database Description and Users Guide Version 3.0. USDA Forest Service, Forest Inventory and Analysis Program, 2007. Available at: http://www.fia.fs.fed.us/ tools-data/docs/pdfs/FIADB_user\%20guide\%203-0_P3_6_01_ 07.pdf. Accessed March 30, 2008.

61. Dixon GE (Comp.). Essential FVS: A user's guide to the Forest Vegetation Simulator. Internal Report. USDA Forest Service, Forest Management Service Center. Fort Collins, CO, 2002. Available at: http://www.fs.fed.us/fmsc/ftp/fvs/docs/ gtr/EssentialFVS.pdf, Accessed on: April 7, 2008.

62. Kaplan S, Garrick BJ. On the quantitative definition of risk. Risk Analysis, 1981; 1:11-27.

63. Moilanen A, Wintle BA. Uncertainty analysis favours selection of spatially aggregated reserve networks. Biological Conservation, 2006; 129:427-434.

64. Moilanen A, Wintle BA, Elith J, Burgman M. Uncertainty analysis for regional-scale reserve selection. Conservation Biology, 2006; 20(6):1688-1697.

65. Levy JK, Hipel KW, Kilgour DM. Using environmental indicators to quantify the robustness of policy alternatives to uncertainty. Ecological Modelling, 2000; 130:79-86.

66. White D, Kimerling AJ, Overton WS. Cartographic and geometric components of a global sampling design for environmental monitoring. Cartography and Geographic Information Systems, 1992; 19(1):5-22.

67. Coulston JW, Koch FH, Smith WD, Sapio FJ. Developing survey grids to substantiate freedom from exotic pests. Pp. 91-97 in McRoberts RE, Reams GA, Van Deusen PC, McWilliams WH (eds). Proceedings of the Eighth Annual Forest Inventory and Analysis Symposium, October 16-19, 2006, Monterey, CA. Gen. Tech. Rep. WO-79. Washington, DC: U.S. Department of Agriculture, Forest Service, 2009.

68. French SD. Decision Theory. New York: Ellis Horwood, 1988.

69. Sharov AA, Colbert JJ. A model for testing hypotheses of gypsy moth Lymantria dispar L., population dynamics. Ecological Modelling, 1996; 84:31-51.

70. Wald A. Statistical decision functions which minimize the maximum risk. Annals of Mathematics, 1945; 46(2):265280. 